Universidad y Salud

CARTA AL EDITOR

\title{
Dolor perineal en relación con las tasas indiscriminadas de episiotomía
}

Sr. Editor, de acuerdo con el artículo: "Caracterización del dolor perineal postparto en puérperas"(1), vengo a través de esta Carta a difundir el conocimiento técnico y científico sobre las notas del manuscrito publicado en el año 2016 en la Revista Universidad y Salud. Además de ser Enfermero Obstetra y Profesor, confieso a la Junta Editorial, a los lectores y a los autores del manuscrito que todas las producciones científicas son extremadamente relevantes y significativas en el campo de la Educación y la Investigación. Por esta razón, utilizaré este medio para hacer mis anotaciones relacionadas con las prácticas profesionales y el uso indiscriminado de la episiotomía, especialmente en Brasil.

En el período posparto, se sabe que las mujeres puérperas presentan dolor relacionado con: la paridad y la práctica de la episiotomía(1). El artículo publicado es un estudio observacional, longitudinal prospectivo, de cohorte única, el protocolo de investigación fue aprobado por el Comité de Bioética en Investigaciones del Hospital La Victoria-Instituto Materno Infantil, acotando que acorde con lo consignado en la Resolución 8430 de 1993. El estudio trae notas y resultados de suma importancia, donde, por ejemplo, la mayoría de las laceraciones fueron clasificadas como grado II en el 64,94\% de los casos, el 33,77\% de los casos clasificadas como grado I y sólo el $1,3 \%$ como grado III, presentando un $n=66$ que fueron suturadas(1).

Un estudio descriptivo de corte transversal, en gestantes con parto vaginal, con edad gestacional mayor o igual a 37 semanas, atendidas en el Hospital Universitario San José de la ciudad de Popayán, Colombia, los autores reportan que se obtuvo una muestra aleatoria simple de 197 pacientes, donde se realizó episiotomía en 60 gestantes con una frecuencia de episiotomía del 30,45\% (IC95\%: 24,1-37,3), no constatado diferencias en patologías materna previas al tiempo del expulsivo o en el peso del recién nacido, respecto a los resultados maternos y perinatales se encontró que las pacientes con episiotomía presentaron menor frecuencia de desgarros: $3(5,26 \%)$ frente a $54(39,42 \%)$ de las pacientes sin episiotomía (RP=0,12; IC95\%: 0,04-0,39). El $28,93 \%(n=57)$ de los partos atendidos presentaron desgarro perineal, siendo grado I el 16,75\% ( $n=33$ ), grado II el 11,68\% (n=23), grado III el 0,51\% (n=1), y ninguno grado IV. No se presentaron infecciones o hemorragias posparto(2).

Sólo en casos restringidos se practica la episiotomía de mujeres primíparas o multíparas con episiotomía realizada en un parto anterior. Según la Organización Mundial de la Salud (OMS) y el Ministerio de Salud (MS), el procedimiento debe realizarse en un máximo del 15\% al 30\% de los partos normales. Y para el Enfermero Obstetra, su actuación está legalmente autorizada por la Resolución del Consejo Federal de Enfermería (COFEN) 477/15, sólo cuando es necesario(3,4).

Además del uso indiscriminado de la episiotomía, por ejemplo, en Brasil, añade riesgos para la salud, y la falta de orientación sobre el procedimiento constituye una mutilación genital que causa un trauma a la mujer, afectando el estado psicológico y emocional por el dolor exacerbado en el momento del parto y el trauma posparto, que puede incluso alterar el futuro desempeño sexual(3). La investigación realizada por la Fundación Instituto Oswaldo Cruz (FIOCRUZ) reveló que la práctica rutinaria de la episiotomía alcanza el 56\% en Brasil. A este respecto, la OMS clasificó en 1996 la episiotomía como una práctica perjudicial que debería abandonarse en el ámbito de la Obstetricia, ya que su uso selectivo es más beneficioso ${ }^{(3-5)}$.

En Brasil, las tasas de episiotomía siguen siendo elevadas, en muchos casos, por razones culturales. Las tres razones que llevan a los profesionales del Hospital Universitario de São Paulo, a indicar este procedimiento, se encuentran: la rigidez perineal, la primiparidad y la prematuridad. Por otra parte, el sufrimiento fetal identificado 
por anomalías en el patrón de los latidos cardiovasculares, puede llevar a los profesionales a realizar una episiotomía para acortar el período de expulsión del parto. Y las principales justificaciones para la adopción rutinaria de la episiotomía en las mujeres primíparas son la prevención de la laceración perineal, la relajación posterior del suelo pélvico y el traumatismo de la cabeza del feto. Uno de los criterios más citados por los Enfermeros Obstetras para realizar la episiotomía es la rigidez perineal(5-7).

Es necesario que los profesionales involucrados en la atención obstétrica de las mujeres, así como los estudios de esta Revista y otras de carácter nacional e internacional, destaquen el tema haciendo énfasis en las buenas prácticas relacionadas con el parto; repensar sus técnicas, y motivar a que los Enfermeros Obstetras se apropien de los resultados de nuevas investigaciones y actúen a favor de un parto de calidad. Es bien sabido que existen muchos obstáculos para abordar toda la estructura medicalizada del proceso de parto y nacimiento, sin embargo, se espera que este estudio y las futuras publicaciones puedan contribuir a la elaboración de políticas públicas para la atención del parto y nacimiento.

\title{
Gustavo Gonçalves dos Santos ${ }^{1 *}$ orcid.org/0000-0003-1615-7646
}

1. Docente de Pregrado en Enfermería en Centro Universitário das Faculdades Metropolitanas Unidas. São Paulo, Brasil.

Conflicto de intereses: Ninguno declarado por el autor.

\author{
*Autor de correspondencia \\ Gustavo Gonçalves dos Santos \\ e-mail: gustavo.nahara@gmail.com
}

\section{Referencias}

1. Medina-Piedrahita PA, Borrero-Cortés C, Herrera-Gómez PJ, Ospina-Diaz JM. Caracterización del dolor perineal postparto en puérperas de Bogotá, Colombia. 2013. Univ Salud [Internet]. 2016;18(3):556-65. DOI: 10.22267/rus.161803.61.

2. Mellizo-Gaviria AM, López-Veloza LM, Montoya-Mora R, Ortiz-Martínez RA, Gil-Walteros CC. Frecuencia de la realización de episiotomía y complicaciones en el servicio de obstetricia del Hospital Universitario San José, Popayán (Colombia), 2016. Exploración de factores maternos y perinatales asociados a su realización. Rev Colomb Obstet Ginecol [Internet]. 2018 Jun 29;69(2):88-7. Disponible en: https://revista.fecolsog.org/index.php/rcog/article/view/3030

3. Carniel F, da Silva Vital D, de Souza T. Episiotomia de rotina: necessidade versus violência obstétrica. J nurs health [Internet]. 2019;9(2):e199204. DOI: 10.15210/JONAH.V9I2.14425.

4. Pereira Nery VP, Pereira de Lucena GP. Principais tipos de violências obstétricas sofridas pelas parturientes. São Paulo: Revista Recién [Internet]. 2019;9(27):89-98. Disponible en: https://www.recien.com.br/index.php/Recien/article/view/306

5. Aguiar SV, Gonçalves ER, Bezerra LR. Análise da incidência e prevalência de laceração perineal de causa obstétrica em maternidade terciária de Fortaleza-CE. Rev Med UFC [Internet]. 2019;59(1):39-43. DOI: 10.20513/2447-6595.2019v59n1p3943.

6. Albuquerque Guimarães NN, Rodrigues da Silva LS, Pontes Matos D, Albuquerque Douberin C. Análise de fatores associados à prática da episiotomia. Revista de Enfermagem UFPE online [Internet]. 2018;12(4):1046-53. DOI: 10.5205/1981-8963v12i4a231010p1046-1053-2018.

7. Organização Mundial da Saúde. Prevenção e eliminação de abusos: desrespeito e maus-tratos durante o parto em instituições de saúde. 2014.

Disponible en: https://apps.who.int/iris/bitstream/handle/10665/134588/WHO_RHR_14.23_por.pdf;jsessionid=345CD500C297775A44 EC468721A97FB5?sequence=3 